\title{
A FORMAÇÃO PROFISSIONAL NUMA INDÚSTRIA AUTOMOBILÍSTICA MINEIRA: SEDUÇÃO, PADRONIZAÇÃO E INTERNACIONALIZAÇÃO
}

\author{
ANTÔNia Vitória Soares Aranha
}

\begin{abstract}
RESUMO: Síntese de uma pesquisa sobre uma indústria automobilística, situada em Minas Gerais. ${ }^{1}$ Essa pesquisa, baseada fundamentalmente em dados empíricos e levantamento documental, procurou inserir a formação profissional implementada pela empresa em transformações e objetivos mais amplos pelos quais essa empresa e o grupo internacional ao qual ela pertence ${ }^{2}$ passaram e ainda passam, em escala mundial, tais como a Fábrica Racionalizada, a construção da EmpresaRede, entre outros. Concluiu apontando a existência de uma sintonia entre as inovaçôes em curso e os objetivos da empresa e do Grupo A Internacional e a formação profissional realizada por ambos. Sintonia essa nem sempre evidente, mas continuamente presente no processo formativo da empresa.
\end{abstract}

Palavras-chave: Formação profissional. Qualificação. Competências. Racionalização. Empresa automobilística.

\section{Professional training IN AN AUTOMOTIVE INDUSTRIAL COMPANY: ATTRACTION, GLOBALIZATION AND STANDARDIZATION}

ABSTRACT: Fundamentally based on empirical data and documentary research, this paper aims at analyzing the professional training given in an automotive industrial company settled in Minas Gerais (Brazil). It tries to situate this activity within the general frame of changes and aims this manufacturer and the International Group to which it belongs have been implementing on an international scale, such as "Rationalized Plant" and the building up of a "Net Company", among others. Grounded on the analysis of interviews, pedagogic resources and com-

Doutora em Educação e professora adjunta da Faculdade de Educação da UFMG. E-mail: antoniavitoria@uol.com.br 
pany documentation, it concludes a harmonizing processes exists and occurs within both the company and this international group with regard to their aims and the training given. Although not always in evidence, such syntony, continuously permeates the company's training process as a whole.

Key words: Professional training. Qualification. Competences. Rationalization. Automotive industrial company.

\section{Introdução}

$E$ ste trabalho é uma síntese de uma pesquisa de doutorado, desenvolvida na Empresa A. Tal pesquisa partiu do pressuposto de que essa montadora de automóveis se constitui numa realidade expressiva em Minas Gerais e no Brasil.

Inicialmente, levantaram-se algumas interrogaçôes tais como: O que faz dessa empresa uma realidade tão específica, encravada no coração das Minas Gerais? Como se constituiu sua força de trabalho? Que mecanismos de sobrevivência e ampliação ela consegue adotar?

Procurou-se, também, agregar a estas interrogações outras mais específicas, relativas à área educacional: Como se dá a formação profissional na montadora? Como essa formação se relaciona com a estratégia mais global da empresa, visando a maior racionalidade e lucratividade? Que tipo de sujeito trabalhador a empresa está ajudando a conformar? A formação, apesar de ser um processo educacional, contribui ou não para aumentar a subsunção dos trabalhadores ao ideário da empresa? Quais as particularidades do processo pedagógico da empresa, implementado por seu esquema de formação profissional? Como ele se relaciona com o chamado Modelo de Competências, a última palavra em qualificação e formação do empresariado internacional?

\section{Empresa automobilística: racionalização, controle e sedução}

A Empresa A era, até 1999, a única montadora de automóveis instalada em Minas Gerais. Implantou-se na região da Grande Belo Horizonte, em 1976, num acordo polêmico, envolvendo enormes benefícios do governo do estado. É hoje a maior unidade do Grupo A no mundo em produção, tendo atingido em 1977 o recorde de 2.300 veículos produzidos em um só dia. Segundo informações da empresa, 
dados coletados em 1996, mas expressivos da sua importância, ela é a segunda maior montadora brasileira, a empresa número um de Minas Gerais e a maior exportadora privada do país.

Essa montadora, porém, é apenas uma das peças de um grande conglomerado internacional, o Grupo A, composto de diversos tipos de empresas: automobilísticas, de veículos industriais, de máquinas agrícolas, de aviação e até mesmo um clube de futebol, o Juventus italiano. O Grupo opera em 62 países, com 888 empresas que empregam cerca de 242 mil pessoas (dados do site internacional do Grupo A). Segundo a revista Exame, em seu anuário "Maiores \& Melhores" de 1998, o Grupo A é hoje o maior conglomerado industrial do Brasil, composto também da montadora de automóveis, de fábricas diversas, de bancos etc.

Desde a sua implantação, a Empresa A tem adquirido enormes índices de produtividade e lucratividade (Bresciani, 1997; Neves, 1996). E vinha também aumentando progressivamente o número de trabalhadores, até que em 1998 ocorreu uma verdadeira onda de demissões na

\section{Tabela 1}

(Demissōes de Trabalhadores da Empresa A)

\begin{tabular}{|l|c|c|}
\hline MÊS & $\mathbf{1 9 9 7}$ & $\mathbf{1 9 9 8}$ \\
\hline Janeiro & 62 & 123 \\
\hline Fevereiro & 93 & 178 \\
\hline Março & 105 & 378 \\
\hline Abril & 50 & 975 \\
\hline Maio & 120 & 194 \\
\hline Junho & 61 & 107 \\
\hline Julho & 34 & 140 \\
\hline Agosto & 82 & 200 \\
\hline Setembro & 74 & 1.818 \\
\hline Outubro & 118 & 2.082 \\
\hline Novembro & 137 & 2.011 \\
\hline Dezembro & 247 & 1.339 \\
\hline Total & 1.183 & 9.545 \\
\hline
\end{tabular}

Fonte: Sindicato dos Metalúrgicos da Região da Empresa A. 
empresa e milhares de empregados foram excluídos e terceirizados. Se entre 1989 e 1998 ela aumentou o número de seus trabalhadores de 11.605 para cerca de 24.000 , as demissões e terceirizações reduziram drasticamente este último número (vide tabelas 1 e 2 ).

\section{Tabela 2}

(Terceirizações na Empresa A - ano de 1998)

\begin{tabular}{|l|c|}
\hline \multicolumn{1}{|c|}{ MÊS } & TERCEIRIZAÇŌES \\
\hline Julho & 98 \\
\hline Agosto & 140 \\
\hline Setembro & 1583 \\
\hline Outubro & 850 \\
\hline Novembro & 316 \\
\hline Dezembro & 300 \\
\hline Total & 3.287 \\
\hline Demais meses & 750 \\
\hline Total Geral & 4.037 \\
\hline
\end{tabular}

Fonte: Sindicato dos Metalúrgicos da Região da Empresa A. Inclui apenas os trabalhadores com, no mínimo, um ano de casa.

Porém, se ela detém índices significativos na produção e no lucro, não se pode dizer o mesmo quanto aos salários pagos aos trabalhadores, os menores da indústria automobilística nacional, segundo informações do Sindicato dos Metalúrgicos da Região da Empresa A.

$\mathrm{Na}$ verdade, seu crescimento não se deve, fundamentalmente, à introdução de inovação em tecnologia fixa. Ainda que haja avanços na introdução de novas tecnologias e que, seguramente, esse avanço tenha possibilitado aumentos de produtividade da empresa, ela não foge ao padrão nacional no qual o investimento em tecnologia de base fixa é ainda pequeno (Carvalho, 1996; Bresciani, 1997; Pires, 1997). O ponto crucial das mudanças e do sucesso da Empresa A encontra-se nas alterações realizadas na gestão e na organização do trabalho (Neves, 1998).

Uma dessas inovações é a chamada Fábrica Integrada, com duas características centrais: a aplicação do conceito de fornecedor e cliente, 
possibilitando melhorias contínuas na produção e a implantação das Unidades Tecnológicas Elementares (UTEs), “onde se trabalha em equipe e onde coexistem - no mesmo tempo e no mesmo espaço - os setores de manutenção e de qualidade" (Pimenta, 1996, p. 179. Tradução nossa).

As UTEs, embora expressem a introdução do trabalho em equipe na empresa, no seu interior mantêm, porém, a divisão do trabalho, com tarefas específicas para cada integrante. Essa divisão do trabalho leva autores como Carvalho (1996) e Neves (1996) a afirmarem que as práticas organizacionais da empresa se aproximam do chamado taylorismo flexivel.

$\mathrm{Na}$ construção da Fábrica Integrada a empresa implantou o Controle da Qualidade Total em 1989. A partir daí, ela introduz o esquema participativo dos trabalhadores, desenvolve a ideologia da "grande família" e intensifica o ritmo de produção, entre outras iniciativas.

Para a implantação do seu Programa de Qualidade, a Empresa A fez um colossal investimento em treinamento e introdução de ferramentas, ${ }^{3}$ ao lado da inauguração de diversos mecanismos de participação consentida, como uma das maneiras de garantir a adesão do trabalhador aos objetivos e às metas da empresa.

$\mathrm{O}$ processo de racionalização da empresa avançou significativamente em 1998. Nesse ano, o Grupo A como um todo promoveu uma ampla terceirização interna, ou seja, criou ou desenvolveu empresas no interior do próprio grupo, voltadas para uma única atividade, buscando, em contrapartida, atender ao conjunto das necessidades do conglomerado. Assim, ela implementou uma empresa responsável por toda a manutenção do Grupo A, inclusive da Empresa A, outra empresa que fabrica componentes automotivos e o Instituto que atua unicamente na formação profissional do grupo. ${ }^{4}$ Dessa forma o Grupo A implementou a chamada Empresa-Rede.

Para garantir a implantação dessas mudanças, a empresa contou com a passividade e mesmo a aquiescência dos seus trabalhadores. Um dos indicativos dessa constatação é o baixo índice de sindicalização dos trabalhadores. Ao passo que a sindicalização da Volkswagen no ABC atingia $87 \%$ dos trabalhadores, a da Ford no Ipiranga (SP) atingia 64,8\%, a da Volvo em Curitiba atingia 25,1\%, a sindicalização na Empresa A não passava dos 10,3\% dos trabalhadores em 1997 (Bresciani, 1997, p. 34). E, de acordo com informações de um dos diretores do Sindicato dos 
Metalúrgicos da Região da Empresa A (1999), esse porcentual ficou ainda mais diminuto nos anos posteriores, chegando a se ter apenas pouco mais de 200 sindicalizados, quando a empresa contava com mais de 24 mil trabalhadores.

Podemos afirmar que vários fatores corroboram com essa situação: há nessa empresa desde uma política deliberada de anulação da intervenção sindical, já que o seu esquema participativo não comporta dimensōes coletivas de intervenção dos trabalhadores, até dificuldades de entendimento da nova realidade pelos dirigentes sindicais, passando pela situação particular da economia mineira e regional de contar com apenas uma única montadora de veículos, até 1999, o que intensifica o temor do desemprego. Dessa forma, sistematicamente, a Empresa A tem expulsado dirigentes sindicais de dentro da empresa, impedidos até mesmo de entrar para trabalhar, tem pressionado os trabalhadores a se "dessindicalizarem" e usado fortes esquemas repressivos para conter qualquer tentativa de mobilização desses trabalhadores.

Um dos componentes dessa política de silenciamento é o processo de seleção dos trabalhadores: a Empresa A recorre a um esquema particular, a chamada carta de indicação, que termina por reforçar o controle e a subsunção das aspiraçôes dos trabalhadores às da fábrica. Os trabalhadores que possuem a carta, exatamente aqueles mais integrados no esquema da empresa, indicam um parente, um vizinho ou amigo para se candidatar ao ingresso na empresa. E, amparada nesse mecanismo, ela cria uma verdadeira rede de favores e apadrinhamentos na fábrica. "É assim que a ideologia da família A vem se ancorar sobre a realidade das relações familiares" (Neves, 1996). Ninguém entra na empresa se não possuir essa carta de apresentação.

Quanto aos salários, há um aparente paradoxo: são os mais altos de Minas e os mais baixos da indústria automobilística nacional. Essa aparente contradição, porém, longe de se constituir num impulso para a mobilização tem se tornado mais um reforço à hegemonia da empresa na região e no estado. $\mathrm{O}$ trabalhador, receoso de perder o emprego na empresa, torna-se mais dócil às determinaçóes desta.

Mas não é apenas por meio do controle e da repressão que a Empresa A consegue a aquiescência e até mesmo a passividade dos seus trabalhadores. Na verdade, ela utiliza um amplo universo simbólico que seduz e envolve os trabalhadores e extrapola os muros da empresa e mesmo as fronteiras de Minas Gerais. Desse esquema fazem parte as inúmeras festas, desde batizados dos filhos dos trabalhadores até 
casamentos dos funcionários, passando pela festa anual de 15 anos das filhas dos empregados, pela gigantesca comemoração do Dia do Trabalhador, realizada no Mineirão, pelos clubes de lazer, entre outras iniciativas da montadora.

Com relação à sua presença no estado, ela busca atingir um universo bem mais amplo e não apenas na área econômica. Atividades culturais, como a restauração do Palácio das Artes em Belo Horizonte, têm a presença da Empresa A; iniciativas científicas como o projeto Carro Elétrico, desenvolvido juntamente com a Escola de Engenharia da UFMG, é um outro exemplo. E explora também o sentimento de mineiridade, como denunciam Pimenta (1996) e Neves (1996).

Foi dado que a família e a comunidade são consideradas como os pontos altos de referência da vida social em Minas, daí a mineiridade. Elas constituem para a empresa recursos importantes no seu processo de transformação. Daí a utilização das imagens de família, de um envolvimento todo especial no sentido de uma formação comunitária e da representação da Empresa como uma cidade. (Pimenta, 1996, p. 349. Grifos da autora. Tradução nossa)

Buscando construir sua hegemonia cultural/ideológica no interior da fábrica e em Minas, ela impulsiona outras iniciativas: o esquema assistencial e a aparente estabilidade que, até pouco tempo, propiciava aos seus trabalhadores, por exemplo. Assim, além de um completo atendimento médico, a Empresa $A$ oferece ajuda financeira em caso de doença, assistência jurídica, sistema de financiamento de automóveis, clube, festas etc.

Podemos concluir então que a racionalização, o controle e a sedução são os pilares do sucesso do esquema dessa empresa.

\section{O Centro A e o Instituto A - agentes centrais do processo de formação profissional}

Atualmente, para implementar o processo de formação profissional da Empresa A e de todo o Grupo A, e fruto também da racionalização levada adiante pelo conglomerado, há duas instituições centrais: o Centro A e o Instituto A. A chamada formação técnica está situada no Centro A e a parte gerencial e "comportamental" ficou localizada no Instituto A. O Centro A, porém, é dirigido pelo Instituto $A$.

O Instituto A, carro-chefe do setor, foi criado em 1995, com base na experiência do instituto internacional do Grupo A. Segundo 
informaçōes desse Grupo, seu instituto internacional "desenvolve cerca de mil programas de treinamento e 22.000 cursos diferentes para atender a mais de 300.000 pessoas espalhadas pelos seis países em que atua (Itália, Suíça, Espanha, Polônia, Turquia, Brasil e Argentina)”.

De acordo com o diretor-superintende do Instituto A, todo treinamento tecnológico e gerencial do Grupo A foi centralizado nesse Instituto, incluindo o setor comercial. Segundo ele, esse Instituto é uma estrutura estratégica dentro do Grupo A, sempre ajudando nas mudanças organizacionais e tecnológicas do grupo, internacionalmente. "É o braço operacional das mudanças tecnológicas e organizacionais do grupo A", diz ele, na implantação da chamada Fábrica Racionalizada. $\mathrm{O}$ instituto internacional tem um centro de pesquisa no país-sede, na Europa, contando com parceiros diversos, procurando agregar vários cientistas como professores da Harvard University, nos EUA. "O Instituto Internacional é um centro de inteligência de todo o grupo, em nível internacional", afirma o diretor.

Com relação ao Centro A, só de março de 1998 (quando começou a funcionar) a novembro do mesmo ano, realizou treinamentos e cursos para 10.688 pessoas, "fazendo quase 46.000 horas de sala de aula. Quase 750 mil homens/hora, o que significou 5.750 dias de curso" (responsável pelo Instituto A no projeto do Centro A). O grosso desse pessoal atendido vem da Empresa Automobilística A (90\% do atendimento). Porém o número de homens/hora de formação profissional da montadora é ainda pequeno para os padrões nacionais e internacionais: 80 homens/hora. E, até agosto de 1999, segundo o mesmo diretor, suas atividades perfaziam um total de 86.835 horas de salas de aula, 11 mil dias de treinamento e 20 mil pessoas atendidas. E tem a pretensão de tornar-se um centro de referência em termos de formação de recursos humanos no estado, já trabalhando com empresas fora do Grupo A (Brahma, Mannesmann, entre outras).

A formação gerencial e comportamental, realizada diretamente no Instituto A, apresenta algumas particularidades que a diferem da parte técnica. De acordo com o diretor-superintendente desse Instituto, são três níveis de cursos que ele oferece diretamente para a área gerencial de todo o Grupo A: o comportamental ou comodities, o institucional e o estratégico. E, ao contrário do Centro A, que amplia a oferta para setores fora do grupo e para empresas de vários tipos, esses cursos do Instituto A são oferecidos apenas às empresas do conglomerado, para as fornecedoras do grupo e para as concessionárias. Visam a formar fundamentalmente a liderança da fábrica, nos seus mais diversos níveis. 
Para se ter uma dimensão do papel desses cursos e treinamentos da área gerencial, na estratégia global do Grupo A, o próprio diretorsuperintendente agregou um exemplo: a apresentação do novo modelo de leadership (liderança), feita pelo instituto internacional para todos os diretores internacionais do grupo, na Europa, no início de dezembro de 1999. Esse modelo foi construído pelo Instituto A, para a linha de produção, foi aprovado pela cúpula do Grupo $\mathrm{A}$ e terá validade mundial. Daí em diante, caberá ao Instituto $\mathrm{A}$ a implementação desse modelo de liderança, por meio de treinamentos, cursos, ajuda pessoal, entre outros instrumentos.

Com relação aos cursos da área tecnológica em si, centrada no Centro A, há uma enormidade deles, desde aqueles voltados para a iniciação do trabalhador na empresa até os cursos de formação continuada, passando por cursos técnicos e pós-graduados em convênios com o CEFET-MG, a PUC-MG e outras instituiçôes.

Vejamos alguns exemplos desses cursos. Entre os cursos de Educação Antecipada, realizados antes do ingresso do trabalhador na empresa, podemos citar o Projeto de Excelência do Trabalhador e o Trainee de Produção.

- Projeto de Excelência do Trabalhador - realizado em parceria com a FIEMG, com duração de três meses. Comporta atividades em sala de aula e on the job. Neste projeto, "o participante deverá ter um aproveitamento maior ou igual a $70 \%$ dos pontos distribuídos, e seu comportamento também é observado e avaliado pelo CPI (Condutor de Processo Integrado), integrante da UTE, durante o treinamento on the job quanto a freqüência, pontualidade, participação, criatividade, trabalho em time, rapidez e qualidade do trabalho. Podem ocorrer casos de aproveitamento superior a $70 \%$ e o participante não ser admitido em função do seu comportamento observado" (informaçôes do chefe do Setor de Treinamento).

- Trainee de Produção - feito em parceria com o SENAI, atende também a estudantes do último período do curso técnico e de engenharia do CEFET, previamente selecionados pela empresa como seus futuros trabalhadores. Os selecionados fazem estágio de seis meses na empresa e depois são contratados como condutor trainee da UTE. Durante esse período combinam-se atividades em sala de aula e on the job (vide quadro 1, com o Plano Pedagógico do Curso). 


\section{Quadro 1 \\ (Plano Pedagógico do Curso Trainee de Produção)}

\section{Plano Pedagógico}

1. Nome do programa:

Formação Trainee de Produção

2. Instituição executora:

Nome: SENAI - Serviço Nacional de Aprendizagem Industrial

3. Justificativa/Objetivos:

Suprir necessidades e potencializar as áreas produtivas da empresa nos aspectos de treinamento dos operadores, execução de tarefas conforme ciclo de produção, autocontrole e utilização das ferramentas/metodologia adequadas, tendo em vista uma atuação permanente na ótica da política cliente/fornecedor interno e externo e de melhoramento contínuo.

\subsection{Objetivo Geral:}

O curso tem o objetivo de formar multiplicadores altamente capacitados na preparação da mão-de-obra que atua diretamente na fabricação/montagem dos produtos (...), atendendo padrōes de qualidade e preço que os clientes exigem. Esses multiplicadores são o principal elo entre o piso de fábrica e a estrutura organizacional e operativa da empresa.

\subsection{Objetivos Específicos:}

Desenvolver e/ou dotar os participantes de habilidades, conhecimentos básicos e específicos e ainda de atitudes para o desempenho de suas funções:

- treinar e desenvolver os operadores por meio da utilização de técnicas corretas de ensino no trabalho;

- garantir a qualidade do produto por intermédio do monitoramento da prática do autocontrole na execução das atividades por parte dos operadores;

- promover o melhoramento contínuo dos processos, produtos e serviços executados em sua UTE, por mieo da utilização de técnicas coerentes com pesquisas desenvolvidas e adotadas pela empresa, bem como por intermédio da sensibilização dos operadores para participação e facilitação de mudanças. 


\begin{tabular}{|l|l|}
\hline \multicolumn{2}{|c|}{ 4. Conteúdo das habilidades básicas, específicas e gestionais: } \\
\hline Curso & Carga Horária \\
\hline Integração do Grupo & 8 \\
Desenvolvimento do Time & 16 \\
Eficácia de Comunicação & 16 \\
Educação de Adultos & 16 \\
Folha de Operação & 8 \\
Training On The Job & \\
Ferramentas de Qualidade & 24 \\
Metodologia Análise e Solução de Problemas & 16 \\
Estatística Aplicada & 16 \\
Controle Estatístico do Processo & 32 \\
TPM* & 8 \\
CCQ ** & 16 \\
Base Humana - autocontrole & 8 \\
Autocontrole & 8 \\
Indicadores de Qualidade & 4 \\
Primeiros Socorros & 4 \\
Training On The Job & \\
Melhoria Métodos & 16 \\
Análise do Trabalho & 16 \\
Relações Humanas & 16 \\
Liderança & 24 \\
Training On The Job & \\
Tecnologia Automobilística & 40 \\
Específico Área de Trabalho & 80 \\
\hline Total & 392 \\
On The Job & 1.200 \\
\hline
\end{tabular}

* Manutenção Produtiva Total

** Círculos de Controle de Qualidade. 
Entre os cursos de Educação Continuada, realizados após o ingresso do trabalhador na empresa, há diversos exemplos, entre eles o Tecnólogo de Processo Automotivo, o Programa de Qualificação e o Treinamento Técnico Operacional.

- Programa de Qualificação - atinge empregados da Empresa A das áreas operacionais, com primeiro grau completo. Tem, atualmente, duração de seis meses, mas já chegou a durar um ano. É um dos tipos de curso que, seja pela sua duração, seja por seus programas, permitem o acesso ao conhecimento técnico a uma fatia significativa de trabalhadores da empresa.

- Programa de Treinamento Técnico Operacional (TтO) - atinge trabalhadores técnicos da empresa. São de curta duração (aproximadamente uma semana) e voltam-se para a adequação técnica do trabalhador às novas tecnologias introduzidas e a outras mudanças realizadas na sua área de trabalho.

Analisando os programas de alguns cursos pudemos observar que, apesar de voltados para a área técnica, todos têm também uma parte comportamental, seja diretamente por meio de itens como Integração do Grupo, Desenvolvimento do Time, Eficácia de Comunicação, Educação de Adultos, Base humana - autocontrole, entre outros, seja por meio do trabalho com ferramentas da Qualidade Total.

\section{A Gestão do Conhecimento}

Trata-se de um outro esquema, umbilicalmente ligado à formação dos trabalhadores da montadora: uma estrutura voltada para a aferição e certificação das competências dos trabalhadores, de delimitação das demandas de formação e treinamento, bem como da indicação sobre quais trabalhadores e funcionários deverão participar dessas atividades. No dizer da empresa, essa atividade "articulada e contínua" se constitui dos seguintes passos: "1. Análise das necessidades de formação (organizacionais, profissionais e pessoais); 2. Projeção dos percursos de aprendizagem; 3. Planejamento dos interventos de formação; 4. Operacionalização e 5. Avaliação dos resultados" (documento da Empresa A, 1999).

Essa Gestão é composta por três setores: Gestores do Conhecimento, Antenas do Conhecimento e Avaliação de Competências, o Professional. É fruto de um processo iniciado mundialmente pelo Grupo A internacional. 
O Professional volta-se para os gerentes, os elos (analistas plenos e seniores), ou seja, para as lideranças. E isso não é gratuito. Para a Empresa A e para o Grupo A em geral, a liderança exerce um papel formativo decisivo.

As lideranças contribuem pessoalmente para o desenvolvimento das competências dos profissionais (...), já que são capazes de gerar e transmitir o conhecimento. O líder deve ser treinador e precisa ter generosidade para compartilhar o que sabe, formando colaboradores mais competitivos e que geram melhores resultados. (Documento da Empresa A, 1999; grifos do autor)

Essa atividade comporta a análise de dois grandes blocos: o Conhecimento e o Comportamento Organizativo. A análise do conhecimento de cada líder enfatiza três áreas: Infra-Estrutura da empresa, Recursos Humanos e Economics (a parte financeira como balanços, indicadores etc). Dessa forma, a avaliação do conhecimento da liderança, portanto, agora é menos específica que geral.

Quanto ao comportamento organizativo, a avaliação de competências definiu dez aspectos, idênticos para todos os setores do Grupo A, em escala mundial: trabalho em equipe, responsabilidade, cooperação, entre outros.

A avaliação de competências no Professional é realizada por um grupo de avaliadores. Pretende-se com isso quebrar a subjetividade que, segundo a empresa, estava muito presente no método clássico de avaliação, pelo qual o funcionário era avaliado apenas por sua chefia imediata. Deverá ser realizada a cada dois a três anos e para sua concretização foi estabelecida uma escala de avaliação, pela qual se tenta dosificar e quantificar o conhecimento apresentado e a ser adquirido pelo avaliando.

O Professional comporta também um esquema de certificação, feita por outro grupo, de pessoas, diferente daquele que fez a avaliação, com o intuito de se estabelecer uma triagem da avaliação feita. Essa certificação tem impactos na remuneração fixa do empregado, embora a empresa admita que ainda não estruturou, completamente, um esquema de compatibilização entre resultados obtidos e a remuneração.

A avaliação também tem efeitos sobre o processo de formação profissional do funcionário, na medida em que a posição que estes venham a ocupar numa escala de 0 a 256 (variação entre o mínimo e o máximo de pontos possíveis de serem obtidos na avaliação das competências no Professional) determina as medidas que a empresa 
pode tomar no sentido de melhorar seu desempenho. Assim, aqueles cujos resultados são inferiores a 80 pontos devem ser submetidos a treinamento, a fim de se tornarem eficientes nas competências em que se mostraram deficitários. Há, portanto, um programa de formação, articulado com a avaliação das competências. Programa este apresentado ao Instituto A, que dá o veredicto final quanto aos pacotes de cursos a serem desenvolvidos.

Visando a facilitar o processo de avaliação, é construído o perfil ideal pelo setor responsável, o Departamento Operacional (DO). Para determinada atividade é estipulado o perfil ideal do funcionário, com pontuaçôes para cada competência. Esse perfil serve de base para o funcionário se orientar dentro da sua avaliação e auxilia também no recrutamento, constituindo a base para os processos avaliativos realizados.

Se o Professional se volta para a área gerencial, para a liderança da empresa, os Gestores do Conhecimento atuam na área industrial, no setor operacional. São cinco gestores que coordenam em full time (atualmente só realizam essa atividade na empresa) o controle de avaliação de competências nessa área. Esses cinco gestores se distribuem nas áreas de fabricação: prensas, funilaria, pintura, montagem final, mecânica.

É com base nas avaliações coordenadas pelos gestores que se delimitam as demandas de cursos e treinamentos. Feito isso, os gestores encaminham os resultados para o setor de Recursos Humanos que, por sua vez, estabelece com o Instituto A as atividades a serem realizadas para a área industrial, levando-se em consideração fatores operacionais tais como o custo/benefício.

As avaliaçōes referem-se a duas situaçōes: a Figura Profissional e o Processo, e têm como objetivo "verificar a criticidade e o desempenho do processo" (Gestor do Conhecimento).

A avaliação da Figura Profissional, equivalente ao processo do Professional, ocorre estabelecendo-se também um perfil ideal de uma figura profissional (uma função, um líder etc). Define-se o papel da figura, a atividade que desempenha, os conhecimentos necessários (competências) e o nível desses conhecimentos (profundidade das competências). O diagnóstico a ser feito sobre o avaliado parte da comparação entre o perfil e a realidade, ou seja, entre o perfil ideal e a pessoa que desempenha a função.

Um dos instrumentos auxiliares para construir o perfil ideal da figura profissional é o Dicionário de Competências. Sua construçãoo obedece ao seguinte procedimento: seleciona-se a competência e ela é organizada com um tí- 
tulo; faz-se, a seguir, a descrição da competência, e a prescrição de como cada nível (de 0 a 2 ) deve trabalhar com ela.

Outra situação a ser avaliada é o Processo, ou seja, a atividade do trabalho. E, nesse caso, considera-se o processo nas suas etapas, envolvendo, portanto, mais de uma figura profissional. Assim, estabelecem-se as competências necessárias para funções diferentes, em níveis diferentes e para processos diferentes.

E, tal como na avaliação das competências da figura profissional, constrói-se a demanda e depois o plano de formação.

E, por fim, como última atividade da Gestão do Conhecimento há, ainda, as Antenas do Conhecimento. São 34 pessoas trabalhando em part time, ou seja, não ficam exclusivamente por conta dessa atividade, mas, simultaneamente, realizam atividades normais dos setores onde se encontram. Elas atuam como os Gestores do Conhecimento, mas situamse na área administrativa, realizando, segundo o gerente de $\mathrm{RH}$, a avaliação por processo.

É dessa forma que a Empresa Automobilística A avalia as competências dos seus trabalhadores e funcionários e como define, em parceria com o Instituto A, as demandas formativas e o programa de cursos e treinamentos a serem realizados. Avaliação que se pretende, tanto quanto possível, objetiva e, portanto, neutra, científica, numa visão positivista de ciência.

Para tanto deve-se apoiar em parâmetros aparentemente naturais, lógicos, tomados como critérios para um processo contínuo de avaliação/capacitação dos trabalhadores da empresa. Esses parâmetros, evidentemente, guardam estreita ligação com o perfil de trabalhador a ser desenvolvido na e pela empresa.

\section{Notas conclusivas}

\section{Esquema mundial de formação de novo tipo de trabalhador}

As definições relativas à Empresa $\mathrm{A}$, sediada em Minas Gerais, são tomadas internacionalmente a partir do seu centro, na Europa. A montadora é uma parte importante desse mecanismo, mas com autonomia bem reduzida. Claro, isso não é um dado novo, o que há de novo são os aspectos incluídos no controle da matriz e mesmo a maneira de exercer esse controle. 
Entre as definições internacionais encontram-se a construção da Fábrica Racionalizada e da Empresa-Rede. Evidentemente, o perfil de trabalhador e as definições organizacionais, entre outras, inserem-se nessas perspectivas. Tudo isso, no caso da Empresa A, com um tempero próprio, adaptando-se às condiçôes da economia e da cultura brasileira e local, o que lhe dá um sabor de "mineiridade".

Com relação à formação profissional, ao aferimento e desenvolvimento de competências, a regra é a mesma. O próprio Instituto A foi criado sob essa perspectiva. Nunca é demais recordar as palavras do seu diretor-superintendente, quando afirma tanto a importância do Instituto A para o Grupo A, no sentido de impulsionar as mudanças organizacionais e tecnológicas do grupo, quanto o seu caráter internacional.

Estamos, portanto, diante de um complexo esquema de formação profissional e humana: globalizado, padronizado e rigidamente controlado. Não se trata de uma experiência isolada, ainda que muito instigante, de uma indústria automobilística instalada no país. Estamos perante uma estratégia internacional de garantia de produtividade e competitividade, em que o fator humano é um aspecto estratégico.

Talvez aí resida a novidade, se se pode caracterizar assim, do novo esquema adotado: a globalização vai atingindo aspectos antes inimagináveis, como os padróes de aferimento de competências e um perfil internacional de trabalhadores. Dessa forma, o Instituto A vem perseguindo a produção de um tipo padronizado de trabalhadores e, para isso, segundo o diretor-superintendente, os indicativos de formação, sejam no Brasil, na Europa, na Argentina ou em Marrocos, devem ser os mesmos.

Pode-se concluir, portanto, que essa talvez seja uma grande característica de todo o Grupo A: mesmo o fator humano é trabalhado internacionalmente. Buscam-se referenciais padronizados de perfil de trabalhadores, de lideranças e gerências. Possivelmente, assegura-se assim a capacidade de deslocamento regional dos trabalhadores e empregados do grupo, pelo menos nos setores que garantem o jeito de ser no Grupo A.

\section{Instituto A, Intelectual Orgânico do Grupo A}

O diretor-superintendente do Instituto A é explícito ao indicar que esse novo "padrão de trabalhador" é construído tendo como peçachave a liderança da empresa ou o leadership.

Pode-se afirmar, assim, que a liderança desempenha o papel de vasos capilares na implantação, no enraizamento e na consolidação da 
Fábrica Racionalizada. São os prepostos, caracterizados por Gramsci (1988), os empregados especializados, capazes de disseminar as diretrizes gerais estabelecidas pelos intelectuais orgânicos do Grupo A. Essa capilaridade chega até ao chão-de-fábrica, por intermédio dos dirigentes das UTES, transformados em multiplicadores, como também por meio dos trainees, e é reforçada no processo formativo continuamente. Um dos indicadores disso é a atribuição, conferida aos instrutores, da função de facilitadores, designação que aponta para uma intencionalidade bem definida em termos de objetivos, padrões e comportamentos a serem desenvolvidos no processo pedagógico.

Se a liderança constitui os prepostos, podemos concluir que o Instituto A é o intelectual orgânico desse conglomerado ou, pelo menos, faz parte da intelectualidade orgânica do Grupo. Não estamos diante apenas de uma empresa que coordena o processo de formação profissional do Grupo, papel por si só de extrema importância. Estamos perante uma estrutura que define padróes, que testa modelos, que pesquisa, sistematiza e controla a disseminação de um perfil de funcionários e de trabalhadores em geral, em escala internacional. Não é gratuita, portanto, a frase do diretor-superintendente - "o Instituto A é a inteligência do Grupo A".

Esse papel construtor englobou o recurso ao desenvolvimento da ciência e da técnica, no sentido de afirmar a hegemonia dos interesses empresariais. O mesmo superintendente informa que entre os colaboradores do Instituto $A$ internacional encontram-se pesquisadores de diversos países, de centros de excelência internacionais. A produção da ciência e da técnica no contexto atual é feita de maneira centralizada, envolvida em toda uma trama de poder e de disputa de poder. Contar com o conhecimento científico e com o desenvolvimento técnico hoje se constitui também um recurso à consolidação da hegemonia cultural, política e ideológica do Grupo A.

Ainda recorrendo ao aporte gramsciano, esse processo ocorreu, na Empresa Automobilística A, tendo em vista uma "ampla reforma intelectual e moral" de seus funcionários, principalmente por meio da Fábrica Racionalizada e do estabelecimento da Empresa-Rede. Criouse todo um esquema comunicacional, simbólico e participativo, impulsionaram-se valores culturais, reforçaram-se referenciais pedagógicos coerentes com esses objetivos. E essa reforma, é preciso observar, não se esgotou: um dos seus atributos é o contínuo movimento do aperfeiçoar-se, intensificar a racionalização, aprimorar o padrão. A Gestão de Competências, a criação do Instituto A no Brasil, o "enxugamento" da fábrica com a demissão e terceirização de trabalhadores são, entre outros, movimentos recentes desse processo. 
No turbilhão dessa reforma, busca-se o estabelecimento de uma "segunda natureza humana", um perfil adequado de trabalhadores - $o$ operário-esportista (Neves, 1996) ou o trabalhador-individuo (Pimenta, 1996), ou seja, um trabalhador profundamente envolvido na superação contínua de índices de produtividade e de qualidade da empresa, mas também, simultaneamente, submetido e se submetendo a uma trama de sanções e recompensas que compõem esse coletivo próprio da Empresa A. Esquema que, ao mesmo tempo, apela à competição individual e à responsabilidade de cada trabalhador pelo sucesso do time, como um todo. Essa "segunda natureza" tem requintes de sofisticação: passa pelo orgulho de ser trabalhador da Empresa A, orgulho esse que se estende à sua família, atravessa um complexo esquema de aprendizagem contínua, formal e informal, e chega até mesmo à identificação plena da Empresa A como um mundo, como uma cidadela que atende todas as necessidades de vivência societária do trabalhador, anulando outras instâncias como o sindicato.

No processo formativo, a construção do perfil ideal de trabalhador para cada atividade e função, combinada com um processo avaliativo constante, constitui-se em um recurso significativo para o alcance desse objetivo pela montadora. $\mathrm{O}$ parâmetro para o funcionário não é o que ele pode ser dentro das condiçóes objetivas da empresa, mas o que ele deve ser em termos do perfil ideal, considerando que se colocam sempre para os sujeitos dois débitos difíceis de saldar: ele deve se aproximar o mais possível do tipo ideal e esse tipo nunca é estático. Ao contrário, muda conforme vão se alterando as competências que o definem.

Por fim, é bom lembrar que essa natureza é construída com padrões bem definidos internacionalmente, ainda que combine peculiaridades da localização regional da empresa, tal como o pavor de demissôes com a conseqüente dificuldade de reempregar-se.

\section{A formação profissional e a conformação dos trabalhadores da Empresa $A$}

Por intermédio do trinômio "competência técnica/consentimento construído/controle disciplinar permanente", a formação profissional reforça e estimula a reforma intelectual e moral dos trabalhadores, auxiliando na construção dessa "segunda natureza humana".

Relembremos Foucault (1981): o poder não só oprime, mas constrói e constrói, em particular, conhecimento. Ou, como diria Roberto Machado, "o poder disciplinar não destrói o indivíduo; ao contrário, ele o fabrica” (1981). Aliás, reforça-se por meio dessa construção. 
É preciso, portanto, não ter do conhecimento uma visão ingênua, romantizada, ainda quando ele pareça completamente desinteressado, neutro e "científico".

Em alguns momentos, essa "não-neutralidade" do processo formativo da Empresa A é mais evidente - nos programas dos cursos, quando são introduzidos itens que dizem diretamente respeito ao processo organizativo e cultural da empresa como, por exemplo, um dos objetivos do curso Trainee de Produção, desenvolvido em parceria com o SENAI (vide quadro 1).

Nos cursos da área gerencial e comportamental, a relação também é explícita. No curso Liderança Profissional, o objetivo estabelecido é o seguinte: "Compreender e colocar em prática atitudes e comportamentos inovadores em relação aos colaboradores, para bem administrar o papel de 'chefe', por meio de uma liderança que esteja de acordo com as mudanças organizacionais do Grupo A no Brasil”.

E a própria utilização, cada vez mais intensa, do modelo de competências exemplifica largamente esse processo: individualização da aprendizagem, valorização do conhecimento funcional, o saber-ser que direciona o saber e o saber-fazer, a própria responsabilização individual pela manutenção do emprego, o que tangencia igualmente a chamada noção de empregabilidade, entre outros objetivos. São aspectos que, por sua evidência, demonstram a intencionalidade explícita do processo de formação.

No entanto, nem sempre o processo é tão retilíneo e evidente. Podemos dizer que a intencionalidade não-explícita ou encoberta aparecerá em outros momentos. Um deles é a centralização do processo decisório: o que aprender, como aprender, quem deve aprender. Dessa forma, a seleção dos conteúdos surge como um desses aspectos: definido exclusivamente por quem detém o controle do processo, agora de forma mais refinada, por meio do aferimento de competências, submetida ao cruzamento com o perfil ideal de cada função e atividade e voltada fundamentalmente para a busca da qualidade e da produtividade empresarial.

A intencionalidade encoberta aparecerá também na organização do processo pedagógico, na delimitação dos tempos e espaços escolares onde aprender e quando aprender são delimitações da alta gerência.

Ainda que sejam aspectos encontrados em todo o processo pedagógico, é importante reforçar a sua presença na Formaçãa Profissional, ou, por outra, na Formação de Competências do Grupo A. Por 
sinal, a Gestão do Conhecimento reforça essa centralização e retira aspectos democratizantes do processo: os cursos de qualificação profissional, em vias de extinção, antes eram ofertados por intermédio de um "concursão" que, mesmo questionável em vários aspectos, era aberto a todos os operários que cumprissem certos pré-requisitos. Agora, apura-se a centralidade da escolha: os Gestores do Conhecimento é que definem, em conjunto com o setor de RH e com o Instituto A, quem deve fazer os cursos e treinamentos, quando fazê-los, em que instituição e com que finalidade.

Outro aspecto que ilustra a intencionalidade encoberta é o processo de avaliação de competências. Busca-se na Gestão do Conhecimento a maior objetividade e mesmo imparcialidade nas avaliações. No entanto, a subjetividade está presente na medida em que tem que se dimensionar em pontuações o nível de conhecimento do funcionário, suas habilidades e comportamentos. Essa avaliação, dirigida pela liderança da empresa, pode ser uma fonte de controle e de coerção. Mesmo avaliações posteriores aos cursos e treinamentos, como aquela que busca medir a aplicação na prática do conhecimento adquirido, no caso dos Gestores do Conhecimento, são eivadas de subjetividades. Essas avaliações são feitas por meio da observação prática do trabalho, com a aplicação de técnicas que comprovem o resultado dos cursos. Reconhecidas pela própria liderança como as mais complexas, demonstram que a tentativa de objetivação de algo extremamente subjetivo como a aplicação do “aprendido" no processo de trabalho é algo de difícil implementação.

Enfim, há uma sintonia entre o processo formativo e avaliativo da empresa e seus objetivos mais gerais. Até onde essa sintonia é quebrada pela especificidade do processo pedagógico, é uma questão a ser melhor averiguada. A Fábrica Racionalizada, a Empresa-Rede, é, contudo, um forte referencial do trabalho pedagógico em geral, de forma explícita ou implícita.

\section{Modelo de Competências e a realidade da Empresa $A$}

Embora constantemente se refira aqui à aferição de competências, à construção de competências na Empresa $\mathrm{A}$, cabe indagar como o Modelo de Competências é introduzido na empresa. Há particularidades?

Inicialmente, é questionável a existência de "modelos" que se implementam de forma pura e total em qualquer realidade. $\mathrm{Na}$ verdade, quando se fala em modelos, refere-se mais a paradigmas a serem 
implementados, de acordo com a realidade social, política e cultural. O chamado "modelo japonês" é um exemplo disso: constituído de um conjunto de normas, prescrições e objetivos, sua implementação segue linhas distintas quando aplicado em cada realidade concreta. Em decorrência disso, a análise que se segue terá como focos a alteração de um padrão de formação - a qualificação, para outros -, o da competência, e as implicaçôes de diversas ordens que essa mudança ocasiona.

Portanto, afastada a idéia de que há um "modelo" acabado, rígido, a ser seguido, a pergunta pode ser de fato reformulada: Como a Empresa A implementa a construção de competências? Há similaridades com outras experiências internacionais?

O processo formativo nessa Empresa aparentemente seguiria um esquema tradicional - delimitação de cursos e indicação de aprendizes que devem fazê-lo. No entanto, há um processo formativo em curso que perpassa todo o processo produtivo, desde os Círculos de Controle de Qualidade (CCQs) aos programas de comunicação e sugestôes, como o Boas Idéias e Sugestôes (BIS), passando pelo cotidiano das UTEs. Esse processo reforça, juntamente com a formação profissional em si, um jeito próprio de ser do trabalhador da Empresa A, o saber-ser, um dos pilares do modelo de competências, que por seu turno direciona o saber $\mathrm{e}$ o saber-fazer.

Como já foi demonstrado, na formação profissional desenvolvida pela Empresa Automobilística A, os aspectos comportamentais e técnicos estão interligados e há uma forte articulação entre o saber-fazer, o saber e o saber-ser. A utilização de um perfil ideal como referência para a avaliação e construção de competências dos trabalhadores e funcionários da Empresa é um indicativo de como o saber-ser, entremeado com o saberfazer e o saber, direciona essas três dimensōes, o que reforça a noção de competências. $\mathrm{O}$ trabalhador da Empresa A não só deve conhecer e saber aplicar o conhecimento, mas realizar isso de uma maneira própria, particular, altamente comprometido e envolvido com os objetivos definidos pela empresa, preocupado em atender e mesmo superar as expectativas atribuídas à sua atividade. E a formação profissional é uma peça importante dessa engrenagem.

Um dos pilares do "modelo de competências" é a responsabilização individual pela aquisição do conhecimento em contraposição a uma compreensão de formação e qualificação profissional como algo mais amplo, mais social que individual. $\mathrm{O}$ processo da formação profissional 
realizado na Empresa A, incluindo a formação profissional propriamente dita e o processo amplo formativo que ocorre no interior da empresa, é feito com uma forte tentativa de caracterização do acesso ao conhecimento como meramente individualizado. É por seus méritos próprios, ou pela necessidade, que o funcionário fez com que a empresa sentisse dele que o indivíduo é chamado a se "formar", a receber treinamentos e cursos. E há ainda um apelo simultâneo à responsabilização individual pela "coletivização" do conhecimento e das habilidades que foram adquiridas.

Recentemente, a Gerência do Conhecimento generalizou e intensificou outra característica do "modelo de competências": a avaliação contínua, a certificação das competências, a relação entre essa avaliação e a formação profissional. Tudo isso seguindo, nesse caso, um padrão bem definido - tentativa de tornar as avaliações as mais objetivas e impessoais e alteração contínua no que deve ser avaliado, de acordo com as mudanças na produção.

Hyland (1994), Ropé (1997), Araujo (1999), entre outros, apontam a influência do tecnicismo pedagógico no modelo de competências, reforçando a influência da psicologia behaviorista, expressando-se, entre outros aspectos, pelo ensino por objetivos. Analisando-se a maneira pela qual a Empresa A estrutura sua formação profissional, veremos que aspectos tais como o ensino por objetivos, os tipos das avaliações realizadas, os programas de cursos, entre outros, permitem concluir que o seu processo de formação profissional não foge ao chamado tecnicismo pedagógico, conforme atestam os materiais pedagógicos da empresa.

\section{Até onde a Gália está tomada e qual aldeia ainda resiste?}

Se é um engano subestimar o amplo esquema formativo do Grupo A, esquema esse que ocorre nas suas "escolas", no chão-de-fábrica e no cotidiano do trabalho, é um engano de mesmo teor imaginar que esse processo é uma ampla avenida com início, meio e fim, previamente e continuamente estabelecidos, sem atropelos, sem obstáculos. A história não é assim, os sujeitos, apesar de estarem envolvidos num processo de sujeição, não foram varridos do panorama empresarial. Talvez aí resida uma das suas dificuldades: apesar de tudo, os homens não são programáveis como as máquinas. "Senhor general, os homens pensam", diria Brecht.

Pela trajetória mais recente dos trabalhadores da empresa e mesmo do Grupo como um todo, é difícil localizar fissuras nesse 
bloco, aparentemente monolítico, mas algumas brechas podem ser inicialmente localizadas. Apontaremos algumas.

Exploremos mais de perto a relação com o conhecimento. Como já foi afirmado, é preciso não ter do conhecimento uma visão ingênua, romantizada, ou seja, que ele, por si só, contém um quantum de libertação. Mas também, reconheçamos, o conhecimento, ainda que fortemente ideologizado, abre fronteiras, descortina horizontes, dentro de um processo contraditório, evidentemente. É de se perguntar, então, em quem medida o conhecimento "técnico", as técnicas de trabalho em grupo na Empresa A, o reforço aos times, entre outros, permitem ao trabalhador da empresa algum tipo de acesso a um horizonte novo, ainda que, de forma contraditória, reforcem a sujeição do trabalhador. Adquirido o conhecimento, este passa a ser um atributo do sujeito e por ele será utilizado, de acordo com seus interesses e suas conveniências. Como afirmam Ferretti \& Silva Jr. (1999, p. 26) ao se referirem à aquisição de conhecimento pelo trabalhador:

Mas é também contraditório, porque torna o Capital dependente da aquisição de conhecimentos e capacidades de ordem superior por parte da força de trabalho, ao mesmo tempo em que tem de apoiar-se mais no trabalho coletivo e na criatividade e autonomia desta, mas reforçando o individualismo.

Esse conhecimento pode ser apropriado e utilizado em outro sentido pelos trabalhadores da Empresa A? Resposta impossível de ser dada neste trabalho, mas fica aqui como uma interrogação para investigações futuras.

A estratégia gestionária do Grupo $\mathrm{A}$, em escala internacional, é complexa, combina heteronomia e hegemonia (Burawoy, 1990). Ou seja, se falha o consentimento, a coerção, sempre presente ainda que invisível, assume um papel de destaque. Em que medida isso vai de encontro à tão propalada possibilidade de participação e de crítica? Ou, em contrapartida, será que isso não descortina para os trabalhadores que essa participação é limitada e ditada pelos interesses da empresa?

Aí surgem outras questôes: quais são os interesses dos trabalhadores nesse processo? Burawoy (idem) estabelece que há um jogo político no interior do processo produtivo, em que trabalhadores e empresários negociam seus interesses, estabelecem regras (nesse caso, rigidamente controladas pela empresa). Mas, se há o jogo, há opositores e há interesses antagônicos ou pelo menos conflitivos envolvidos. Quais são os interesses dos trabalhadores da Empresa A? Claro que essa pergunta é feita fugindo- 
se de uma visão meramente essencialista, segundo a caracterização de Castro (1994), na qual os interesses dos trabalhadores estão dados de per si, por sua condição histórica. Ou como afirmam Ferretti \& Silva Jr. (1999, p. 25), superando estudos e investigaçóes que reduziram as subjetividades dos trabalhadores a uma única, "a subjetividade do operariado - e este a um corpus homogêneo, identificado e articulado por interesses de classe que se contraporiam, como tal, à classe fundamental que lhe é antagônica".

Concretamente, é necessário delimitar-se em que medida os interesses dos trabalhadores da empresa, ou de boa parte deles, encontram ressonância nesse esquema empresarial. Como e por que participam do jogo da empresa? A pergunta é, portanto, ideológica e histórica. Histórica no sentido de situar esses interesses dentro de um contexto concreto, contraditório e complexo, e ideológica na medida em que não desconsidera que a estrutura capitalista existente cria a oposição fundamental entre as duas classes centrais no capitalismo - operários e capitalistas -, "ao mesmo tempo em que cria, como sempre fez, fissuras no interior da classe trabalhadora visando a sua continuidade" (Ferretti \& Silva Jr., 1999, p. 32).

Recebido e aprovado em fevereiro de 2003.

\section{Notas}

1. Doravante, essa empresa será aqui identificada como Empresa A.

2. Doravante, esse grupo passa a ser aqui identificado como Grupo A.

3. CCQs, CEDAC, CEP, Poka Yoke, TPM, FMEA, Just-in-time, Kanban, Setup, Work-out etc.

4. Aqui chamado de Instituto A.

Referências bibliográficas

ARAUJO, R M L. Competência e qualificação: duas noções em confronto, duas perspectivas de formação dos trabalhadores em jogo. Belo Horizonte, 1999. (Mimeo).

BRESCIANI, P. Os desejos e o limite: reestruturação industrial e ação sindical no complexo automotivo brasileiro. In: LeITE, M.P. (Org.). $O$ trabalho em movimento: reestruturação produtiva e sindicatos no Brasil. Campinas: Papirus, 1997. 
BURAWOY, M. A transformação dos regimes fabris no capitalismo avançado. Revista Brasileira de Ciências Sociais, São Paulo, v. 5, n. 13, 1990.

CARVALHO, R.A.A. Les nouvelles technologies de gestion et la mobilisation de la ubjetivite dans une industrie automobile au Brésil. 1996. Tese (Doutorado) - Université de Paris II, Paris.

CASTRO, N.A. Organização do trabalho, qualificação e controle social na indústria moderna. In: Trabalho e educação. Campinas: Papirus, 1994. (Coletânea CBE)

FERRETTI, J.C.; SILVA JR., J.R. Qualificação como construção e relação sociais: diferentes leituras de autores marxistas. São Paulo: FAPESP, 1999. (Relatório de pesquisa).

FOUCAULT, M. Microfísica do poder. 2. ed. Rio de Janeiro: Graal, 1981.

GRAMSCI, A. Maquiavel, a politica e o Estado moderno. 6. ed. Rio de Janeiro: Civilização Brasileira, 1988.

HYLAND, T. Origens da educação e treinamento baseados em competência: qualificação profissional nacional e o desenvolvimento do Conselho Nacional de Qualificação Profissional. In: Hyland, T. Competência, educação e qualificação profissional nacional. Londres: Cassel, 1994.

MACHADO, R. Introdução. In: Foucault, M. Microfísica do poder. 2. ed. Rio de Janeiro: Graal, 1981.

NEVES, M.M.B.A. A emergência de novos paradigmas de gestão da produção e do trabalho: o caso da Fiat-MG. Belo Horizonte, 1996. (Relatório de pesquisa)

NEVES, M.M.B.A. Impactos da reestruturação produtiva sobre as relações capital-trabalho: o caso Fiat-MG. In: Oliveira, F.; Comin, A.A. (Org.). Os cavaleiros do antiapocalipse: trabalho e política na indústria automobilística. São Paulo: Entrelinhas, 1998.

PIMENTA, S.M. Le tournant de la Fiat mineira: travail, imaginaire et citoyenneté dans l'expérience des travailleurs. Paris: Pantheón-Sorbonne, Institute d'Etude du Développement Economique et Social, 1996.

PIRES, E.L.S. Crise econômica, reestruturação produtiva e emprego: transformações nas montadoras da indústria automobilística no Brasil. 
In: Carleial, L.; Valle, R. (Org.). Reestruturação produtiva e mercado de trabalho no Brasil. São Paulo: Hucitec-Abet, 1997.

ROPÉ, F. Dos saberes às competências. In: Ropé, F.; TAnguY, L. (Org.). Saberes e competência: o uso de tais noções na escola e na empresa. São Paulo: Papirus, 1997. 